\title{
Open source simulation of the pyloric network
} David L Fourie* and Peter Andras

\author{
Address: School of Computer Science, Newcastle University Newcastle upon Tyne, NE1 7RU, UK \\ Email: David L Fourie* - david.fourie@ncl.ac.uk \\ * Corresponding author
}

from Sixteenth Annual Computational Neuroscience Meeting: CNS*2007

Toronto, Canada. 7-12 July 2007

Published: 6 July 2007

BMC Neuroscience 2007, 8(Suppl 2):P8 doi:10.1 I86//47I-2202-8-S2-P8

(c) 2007 Fourie and Andras; licensee BioMed Central Ltd.

\section{Background}

The pyloric network (Figure 1) is part of the stomatogastric ganglion (STG) of crustaceans [1]. The network is a central pattern generator (CPG) that drives the muscles of the pylorus, which is a food filtering organ within the gastric system of these animals. The pyloric network is one of the most researched neural circuits and many details of it are known, including types and numbers of participating cells, connections between these cells, transmitters, receptors and neuron-modulators used by cells within the network [1]. Consequently, this network is an ideal candidate to develop detailed network simulations of neural systems.

Simulations of the pyloric network have been developed since the 1970s [1]. However, these simulations do not include many of the known details about the pyloric network, and produce a behaviour that resembles at high level the behaviour of the biological network, but ignores the behavioural details. These earlier simulations are also application specific, and cannot be easily modified and reused by researchers.

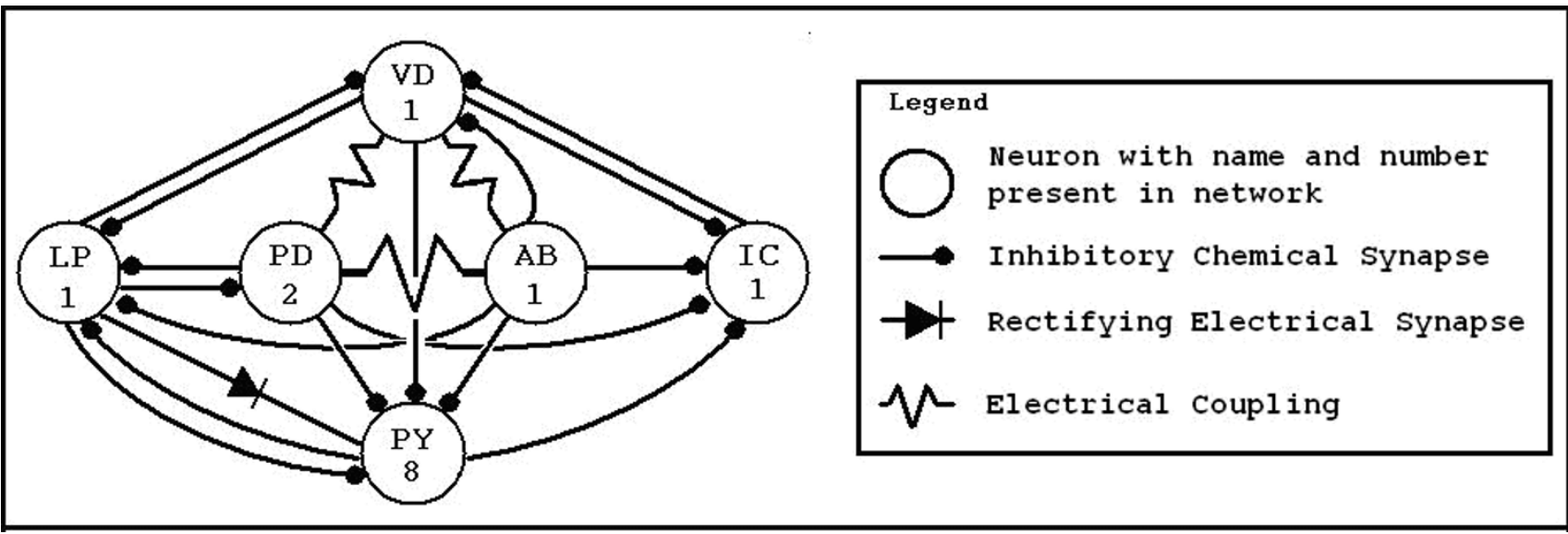

Figure I

A diagram of the pyloric network. The diagram shows the participating neurons, their numbers and the connections between these neurons. 


\section{Methods and results}

We present here a new open source simulation of the pyloric network. The simulation is developed using the Neuron simulation language [2]. Each neuron is simulated using four compartments: soma, primary neurite, axon, dendrite. The primary neurite is connected to all three other compartments. The connections are implemented by linking the axon outputs of neurons to the corresponding dendrite inputs of other neurons. The effects of neuromodulation are implemented in form of changing characteristics of neural connections in response to changes in the values of a multi-dimensional modulation state variable (i.e. each component of the vector indicates the presence and concentration of a neuromodulator, the components being labeled by the corresponding modulator). The values of parameters for the neural compartments are set using the STG neuron database developed by Prinz et al [3]. To determine the right setting of parameters for each cell type we used the simulator attached to STG neuron database [3] to check that the output of our model neurons matches the output of modeled neurons.

\section{Conclusion}

Our simulation is developed as open source software, allowing other users to download the source code and modify it. In this way other researchers may use this detailed simulation of the pyloric network to check experimental assumptions and also possibly to develop simulations of other related networks (e.g. gastric mill network).

\section{References}

I. Harris-Warrick RM, Marder E, Selverston Al, Moulins M: Dynamic Biological Networks. The Stomatogastric Nervous System Cambridge, MA: MIT Press; 1992.

2. Carnevale NT, Hines ML: The NEURON Book Cambridge: Cambridge University Press; 2006.

3. Prinz AA, Billimoria CP, Marder E: Alternative to hand-tuning conductance-based models: construction and analysis of databases of model neurons. Journal of Neurophysiology 2003, 90:3998-40I5.

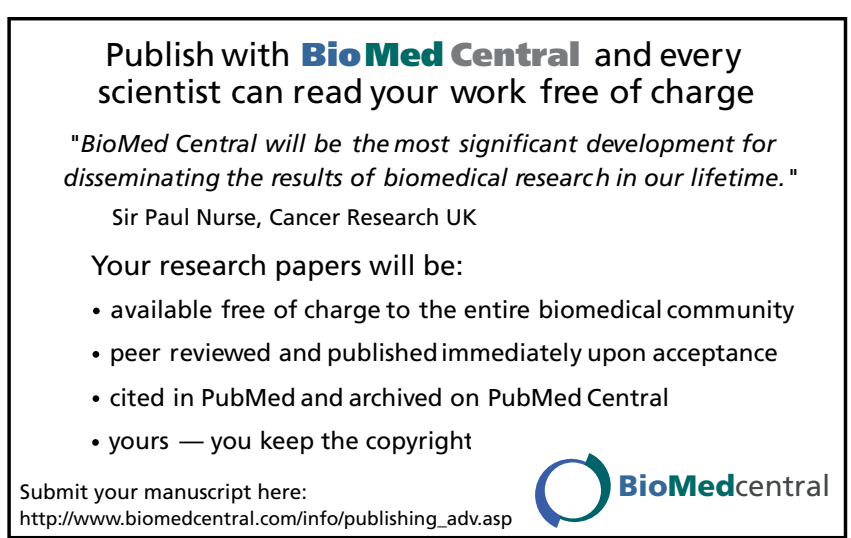

Page 2 of 2

(page number not for citation purposes) 